\title{
Genetic Alterations in Invasive Breast Carcinoma with a Glycogen-Rich Clear Cell Pattern: A Case Report
}

\author{
Carlo De la Sancha ${ }^{a}$ Roberto Ruiz-Corderob Nikolay Popnikolov ${ }^{a}$ \\ aDepartment of Pathology and Laboratory Medicine, Indiana University School of Medicine, \\ Indianapolis, IN, USA; b Department of Pathology and Laboratory Medicine, University of \\ California, San Francisco, CA, USA
}

\author{
Keywords \\ Glycogen-rich clear cell carcinoma $\cdot$ Breast cancer $\cdot$ Next-generation sequencing $\cdot A R I D 1 A$. \\ MAP2K4
}

\begin{abstract}
Invasive carcinoma with a glycogen-rich clear cell pattern (IC-GRCCP) is a rare and understudied subtype of invasive breast carcinoma of no special type (IBC-NST). Here we report the molecular characteristics of a mammary IC-GRCCP diagnosed in a 69-year-old woman. Nextgeneration sequencing of the tumor revealed an inv(1)(p36.12,q32.1) leading to loss-of-function of ARID1A gene, a MAP2K4 truncating mutation (p.E376), MYC amplification, a variant of uncertain significance of PTPRB gene (p.D1848N) and deep deletions of NCKAP5, CCNT2, $M A P 3 K 19, \angle R P 1 B$, and KMT2A. The analysis of the involved pathways shows close resemblance to the ovarian clear cell carcinoma and indicates similarities in the molecular mechanisms of development of glycogen-rich clear cell carcinomas in different organs. Our findings and the literature review suggest new potential strategies for treatment of mammary IC-GRCCP, including epigenetic therapies, checkpoint inhibitors, radiation, or other double-strand DNA breaks-inducing agents. Nevertheless, larger studies are needed to substantiate those ideas.

\section{Introduction}

Invasive carcinoma with a glycogen-rich clear cell pattern (IC-GRCCP), formerly classified as glycogen-rich clear cell carcinoma, is a rare subtype of invasive breast carcinoma of no special type (IBC-NST) accounting for approximately $0.01 \%$ of all breast malignancies [1]. It is characterized by the presence of neoplastic cells with abundant clear cytoplasm that

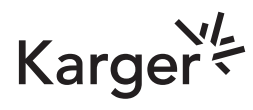




\section{Case Reports in Oncology}

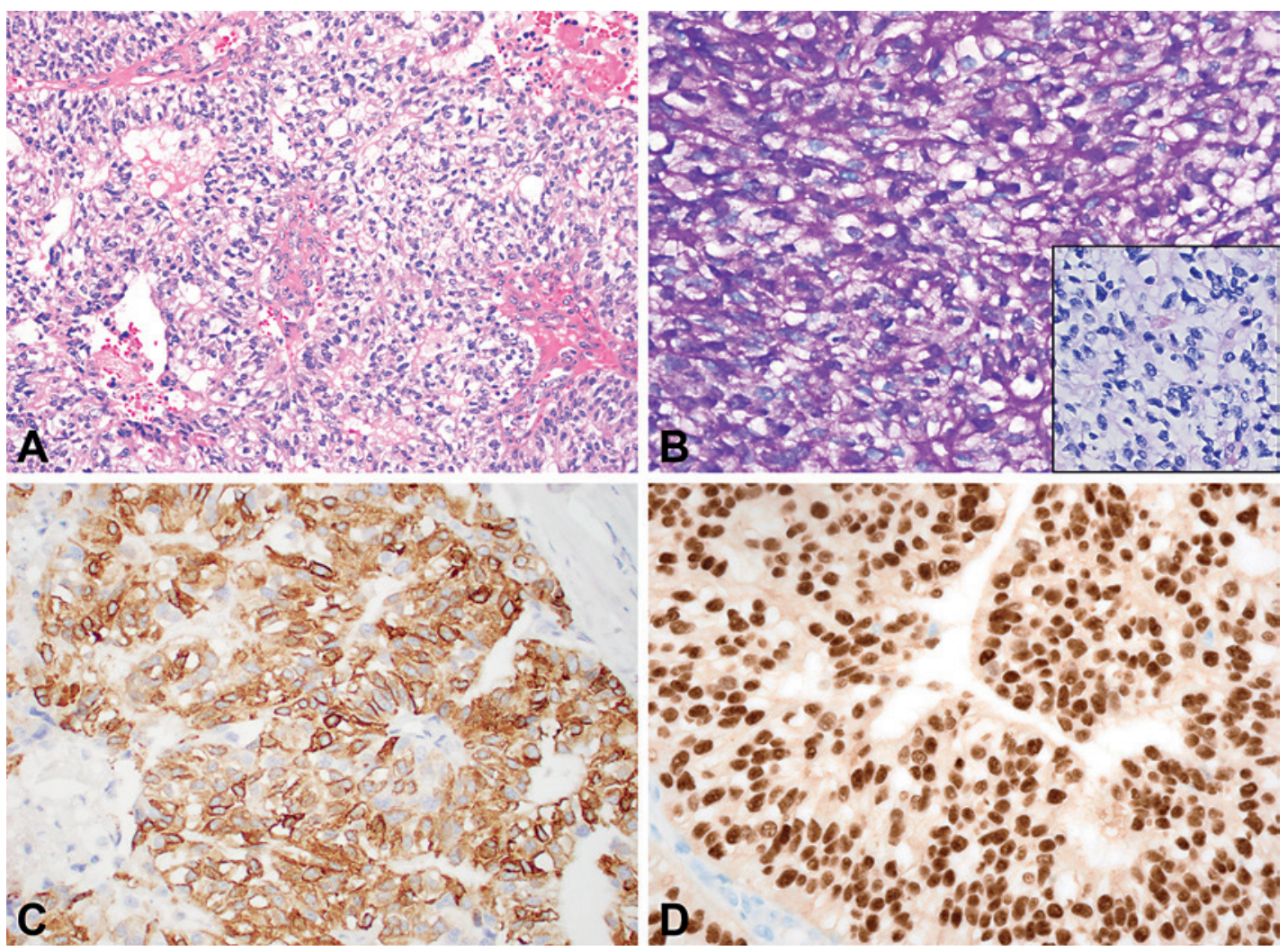

Fig. 1. Microphotographs of the breast tumor. A Hematoxylin and eosin stain. B Periodic acid-Schiff with (inset) and without digestion. C Immunohistochemical stain for mammaglobin. D Immunohistochemical stain for estrogen receptor. Original magnifications, $\times 200$ for $\mathbf{A}, \times 400$ for $\mathbf{C}-\mathbf{D}$.

contains glycogen. Due to the low incidence of this tumor, the information about the specific molecular alterations, their prognostic significance, and potential therapeutic implications is quite limited.

\section{Case Report/Case Presentation}

A 69-year-old woman with no significant past medical history presented with a $1.8 \mathrm{~cm}$ right breast mass. The resection specimen revealed an invasive neoplasm with glandular and solid papillary growth patterns composed exclusively of polygonal cells with clear cell cytoplasm and distinct cell borders (shown in Fig. 1A). Tumor cells were strongly positive for periodic acid-Schiff (PAS) and PAS-diastase sensitive (shown in Fig. 1B). The tumor was also positive for mammaglobin and ER (shown in Fig. 1C-D), while negative for PR, HER2, and PAX-8. The morphologic features and histochemical staining results are consistent with an invasive carcinoma with a glycogen-rich clear cell pattern. The immunophenotype supports a breast primary site of origin.

Tumor-only sequencing using a hybrid-capture next-generation sequencing (NGS) assay was performed using formalin-fixed paraffin-embedded tissue. The NGS panel included the coding regions of 479 cancer-related genes, selected introns of 47 genes, and the TERT promoter. The NGS found alterations in the following genes: ARID1A, KDM5B, MAP2K4, MYC, PTPRB, NCKAP5, CCNT2, MAP3K19, KMT2A, and LRP1B. The details are shown in Table 1. 
Table 1. Genetic alterations in the patient's tumor

\begin{tabular}{|c|c|c|c|}
\hline Gene & Name & Genetic alteration & Gene functions/pathways ${ }^{+}$ \\
\hline ARID1A & $\begin{array}{l}\text { AT-Rich Interaction Domain } \\
1 \mathrm{~A}\end{array}$ & $\begin{array}{l}\text { inv(1)(p36.12,q32.1); large inversion } \\
\text { between exon } 20 \text { of } A R I D 1 A \text { and intron } \\
2 \text { of } K D M 5 B \text { leading to loss-of-function } \\
\text { of ARID1A tumor suppressor gene }\end{array}$ & $\begin{array}{l}\text { DNA and protein binding; transcription } \\
\text { coactivator activity; negative regulation of } \\
\text { transcription by RNA polymerase II }\end{array}$ \\
\hline KDM5B & Lysine Demethylase 5B & $\operatorname{inv}(1)(p 36.12, q 32.1)$ & $\begin{array}{l}\text { Transcription corepressor activity; } \\
\text { chromatin organization and remodeling; } \\
\text { regulation of transcription by RNA } \\
\text { polymerase II }\end{array}$ \\
\hline MAP2K4 & $\begin{array}{l}\text { Mitogen-Activated Protein } \\
\text { Kinase Kinase } 4\end{array}$ & $\begin{array}{l}\text { p.E376* truncating mutation with a } \\
\text { variant allelic frequency of } 87 \% \\
\text { suggestive of loss-of-heterozygosity }\end{array}$ & $\begin{array}{l}\text { Protein serine/threonine kinase activity; } \\
\text { protein tyrosine kinase activity; activation } \\
\text { of MAPK activity; apoptotic process }\end{array}$ \\
\hline PTPRB & $\begin{array}{l}\text { Protein Tyrosine Phosphatase } \\
\text { Receptor Type B }\end{array}$ & $\begin{array}{l}\text { p.D1848N a variant of uncertain } \\
\text { significance }\end{array}$ & Protein dephosphorylation; angiogenesis \\
\hline$M Y C$ & $\begin{array}{l}\text { MYC Proto-Oncogene, BHLH } \\
\text { Transcription Factor }\end{array}$ & Amplification $(5 \times)$ & $\begin{array}{l}\text { DNA-binding transcription factor activity, } \\
\text { RNA polymerase II-specific; negative } \\
\text { regulation of transcription by RNA } \\
\text { polymerase II; MAPK cascade; G1/S } \\
\text { transition of mitotic cell cycle; re-entry into } \\
\text { mitotic cell cycle }\end{array}$ \\
\hline CKAP5 & $\begin{array}{l}\text { Cytoskeleton Associated } \\
\text { Protein } 5\end{array}$ & Deep deletion & $\begin{array}{l}\text { Microtubule bundle formation and } \\
\text { depolymerization }\end{array}$ \\
\hline CCNT2 & Cyclin T2 & Deep deletion & $\begin{array}{l}\text { Transcription elongation from RNA } \\
\text { polymerase II promoter }\end{array}$ \\
\hline МАРЗК19 & $\begin{array}{l}\text { Mitogen-Activated Protein } \\
\text { Kinase Kinase Kinase } 19\end{array}$ & Deep deletion & $\begin{array}{l}\text { Protein serine/threonine kinase activity; } \\
\text { stress-activated protein kinase signaling } \\
\text { cascade; regulation of mitotic cell cycle }\end{array}$ \\
\hline KMT2A & Lysine Methyltransferase 2A & Deep deletion & $\begin{array}{l}\text { Chromatin organization; regulation of } \\
\text { transcription, DNA-templated; apoptotic } \\
\text { process }\end{array}$ \\
\hline$L R P 1 B$ & $\begin{array}{l}\text { LDL Receptor Related Protein } \\
\text { 1B }\end{array}$ & Deep deletion & $\begin{array}{l}\text { Protein and calcium ion binding; receptor- } \\
\text { mediated endocytosis }\end{array}$ \\
\hline
\end{tabular}

${ }^{+}$Selected GO, terms from GeneCards ${ }^{\circledR}$ : The Human Gene Database.

\section{Discussion/Conclusion}

Limited information exists about genetic changes in the IC-GRCCP of the breast. Genetic alterations have been reported in PIK3R1, BRCA2, TP53, PTEN, CDKN2A, BCOR, and EGFR genes $[2,3]$. To our knowledge, there are no reports implicating other known cancer-associated genes, such as ARID1A, MYC, and MAP2K4, in the development of mammary IC-GRCCP. Other genetic alteration, such as the $L R P 1 B$ or KMT2A deletions, may have also contributed to the development of the tumor, but further studies are required to determine their significance since limited information exists.

The AT-Rich Interaction Domain 1A (ARID1A) gene is located within chromosomal region $1 \mathrm{p} 36$. The encoded protein is a component of SWI/SNF chromatin remodeling complexes that is involved in the regulation of gene expression, proliferation, apoptosis, differentiation, and DNA repair [4]. ARID1A confers target specificity to the SNF/SWI complex by recruiting it to the specific sites of chromatin remodeling [4]. ARID1A acts as a tumor suppressor gene and 
De la Sancha et al.: Genetic Alterations in Mammary Carcinoma with a Glycogen-Rich Clear Cell Pattern

is genetically altered or demonstrates loss of protein expression in a wide variety of tumor types [4]. In the TCGA PanCancer Atlas study (http://www.cbioportal.org) genetic alterations of ARID1A gene were found in approximately $5 \%$ of the breast cancers, while abnormal mRNA or protein expression was detected in $4-5 \%$ of the cases.

As a part of the SWI/SNF complex ARID1A participates in differentiation-associated repression of cell cycle genes some of which, such as $M Y C, C D K 1$, and $C C N B 2$, are directly targeted at the time of repression [5]. This suggests synergism between the ARID1A mutation and $M Y C$ amplification, in our case leading to further enhancement of the effect of MYC on the cell cycle.

MAP2K4 is a part of mitogen-activated protein kinase (MAPK) pathways. In response to various stress stimuli MAP2K4 activates Jun N-terminal kinases (JNKs) and p38 MAPKs that control apoptosis, proliferation, differentiation, and cell migration. In our case, we found MAP2K4 p.E376* truncating mutation that involves the DVD domain which contains a docking site critical for MAP2K4 activation by MAP3Ks. This is in agreement with the majority of the studies that suggest a tumor suppressor role of MAP2K4 [6]. Experimental studies have also demonstrated that JNK pathway defects that result in loss of JNK signaling are "driver" mutations in mammary carcinogenesis [7].

Interestingly, the review of the literature shows genetic resemblance between our case and the glycogen-rich clear cell carcinomas from other organs, which indicates similarities in the molecular mechanisms of their development. For example, ARID1A genetic alterations and/or protein downregulation have been reported in up to $62 \%$ of ovarian clear cell carcinomas [8], 26\% of endometrial clear cell carcinomas [9], and $67 \%$ of renal clear cell carcinomas [10]. Our finding of alterations in ARID1A, MYC, and MAP2K4 genes is very similar to the results of Murakami et al. [8], who reported genetic damage involving the SWI/SNF complex, the MYC-CDK2/4-RB1 pathway, and the KRAS-PIK3CA-AKT1-PTEN pathway in 85, 79 , and $82 \%$ of ovarian clear cell carcinomas, respectively. Although we did not detect alterations in the PIK3CA/PTEN pathway in contrast to Murakami et al. [8], the inactivating MAP2K4 mutation in our case may have a similar effect since AKT phosphorylates and inactivates MAP2K4 [11] causing loss ofJNK signaling upon PIK3CA/PTEN pathway activation. Co-existing genetic damage in two of those pathways (PTEN mutation/loss and a CDKN2A mutation) has been reported by Skenderi et al. [2] in one of their five cases of mammary IC-GRCCP.

Some of the genetic alterations in the tumor may have therapeutic implications. For example, experimental data suggest that ARID1A and SWI/SNF-subunit mutations result in epigenetic vulnerabilities in the tumor cells that can be targeted through inhibition of histone deacetylase (HDAC) and/or the catalytic subunit (EZH2) of the polycomb repressive complex 2 (PRC2) [12]. In addition, loss of ARID1A function causes DNA repair deficiency and may confer sensitivity to immune checkpoint inhibitors [13], radiation [14], or other doublestrand DNA breaks-inducing treatments such as PARP and ATR inhibitors [14]. Mutations causing loss of MAP2K4 function sensitize tumors with RAS/RAF dysfunction to MEK inhibitors by inactivating JNK-JUN mediated feedback loop [15]. New anti-MYC therapies using inhibition of $M Y C$ transcription, partner protein dimerization, activating post-translational modifications, and turnover are in pre-clinical and clinical testing phases [16].

In summary, here we report new genetic alterations in mammary IC-GRCCP involving the chromatin remodeling machinery, MYC-CDK2/4-RB1 pathway and JNK pathway and demonstrate molecular similarities in the pathogenesis of clear cell carcinomas with high glycogen contents observed in different organs. More extensive molecular studies are needed to further elucidate the genetic mechanisms of mammary IC-GRCCP and the potential therapeutic opportunities for those patients.

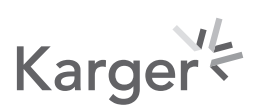




\section{Case Reports in Oncology}

\begin{tabular}{l|l}
\hline Case Rep Oncol 2021;14:500-505 \\
\hline DOI: 10.1159/000514978 & $\begin{array}{l}\text { @ 2021 The Author(s). Published by S. Karger AG, Basel } \\
\text { www.karger.com/cro }\end{array}$ \\
\hline
\end{tabular}

De la Sancha et al.: Genetic Alterations in Mammary Carcinoma with a Glycogen-Rich Clear Cell Pattern

\section{Statement of Ethics}

Written informed consent was obtained from the patient for publication of this case report and any accompanying images. The study was approved by the Institutional Review Board at the University of California San Francisco (IRB\#18-26671).

\section{Conflict of Interest Statement}

The authors have no conflicts of interest to declare.

\section{Funding Sources}

Intradepartmental Research Grant, Department of Pathology, University of California San Francisco.

\section{Author Contributions}

Carlo De la Sancha MD: took the lead in writing the manuscript. Roberto Ruiz-Cordero MD: analyzed NGS data and contributed to the final version of the manuscript. Nikolay Popnikolov MD, PhD: contributed to discussion and supervised the project.

\section{References}

1 Zhou Z, Kinslow CJ, Hibshoosh H, Guo H, Cheng SK, He C, et al. Clinical Features, Survival and Prognostic Factors of Glycogen-Rich Clear Cell Carcinoma (GRCC) of the Breast in the U.S. Population. Jcm. 2019;8(2):246.

2 Skenderi F, Palazzo J, Swensen J, Feldman R, Contreras E, Florento E, et al. Novel targetable biomarkers in clear cell carcinoma of the breast uncovered by molecular profiling: A study of nine cases. Breast J. 2020;26(9): 1781-3.

3 Levva S, Kotoula V, Kostopoulos I, Manousou K, Papadimitriou C, Papadopoulou K, et al. Prognostic evaluation of epidermal growth factor receptor (EGFR) genotype and phenotype parameters in triple-negative breast cancers. Cancer Genomics Proteomics. 2017;14(3):181-95.

4 Pavlidou EN, Balis V. Diagnostic significance and prognostic role of the ARID1A gene in cancer outcomes (Review). World Acad Sci J. 2020;2(2):49-64.

5 Nagl NG, Zweitzig DR, Thimmapaya B, Beck GR, Moran E. The c-myc gene is a direct target of mammalian SWI/ SNF-related complexes during differentiation-associated cell cycle arrest. Cancer Res. 2006;66(3):1289-93.

6 Cunningham SC, Gallmeier E, Kern SE. MKK4 as oncogene or tumor suppressor: In cancer and senescence, the story's getting old. Aging. 2010;2(11):752-3.

7 Girnius N, EdwardsYJK, Garlick DS, Davis RJ. The cJUN NH2-terminal kinase (JNK) signalling pathway promotes genome stability and prevents tumor initiation. eLife. 2018;7:e36389.

8 Murakami R, Matsumura N, Brown JB, Higasa K, Tsutsumi T, Kamada M, et al. Exome sequencing landscape analysis in ovarian clear cell carcinoma shed light on key chromosomal regions and mutation gene networks. Am J Pathol. 2017;187(10):2246-58.

9 Wiegand KC, Lee AF, Al-Agha OM, Chow C, Kalloger SE, Scott DW, et al. Loss of BAF250a (ARID1A) is frequent in high-grade endometrial carcinomas. J Pathol. 2011;224(3):328-33.

10 Lichner Z, Scorilas A, White NM, Girgis AH, Rotstein L, Wiegand KC, et al. The chromatin remodeling gene ARID1A is a new prognostic marker in clear cell renal cell carcinoma. Am J Pathol. 2013;182(4):1163-70.

11 Park HS, Kim MS, Huh SH, et al. Akt (protein kinase B) negatively regulatesSEK1 by means of protein phosphorylation. J Biol Chem. 2002;277(4):2573-8.

12 Fukumoto T, Park PH, Wu S, Fatkhutdinov N, Karakashev S, Nacarelli T, et al. Repurposing Pan-HDAC Inhibitors for ARID1A-Mutated Ovarian Cancer. Cell Rep. 2018;22(13):3393-400.

13 Shen J, Ju Z, Zhao W, Wang L, Peng Y, Ge Z, et al. ARID1A deficiency promotes mutability and potentiates therapeutic antitumor immunity unleashed by immune checkpoint blockade. Nat Med. 2018;24(5):556-62. 
14 Park Y, Chui MH, Suryo Rahmanto Y, Yu ZC, Shamanna RA, Bellani MA, et al. Loss of ARID1A in Tumor Cells Renders Selective Vulnerability to Combined Ionizing Radiation and PARP Inhibitor Therapy. Clin Cancer Res. 2019;25(18):5584-94.

15 Xue Z, Vis DJ, Bruna A, Sustic T, van Wageningen S, Batra AS, et al. MAP3K1 and MAP2K4 mutations are associated with sensitivity to MEK inhibitors in multiple cancer models. Cell Res. 2018;28(7):719-29.

16 Allen-Petersen BL, Sears RC. Mission Possible: Advances in MYC Therapeutic Targeting in Cancer. BioDrugs. 2019;33(5):539-53. 